\title{
Osteogenesis Imperfecta Type II
}

National Cancer Institute

\section{Source}

National Cancer Institute. Osteogenesis Imperfecta Type II. NCI Thesaurus. Code C99001.

A severe form of osteogenesis imperfecta. It is characterized by bone deformities, multiple fractures, underdeveloped lungs, and often death during or after birth due to respiratory abnormalities. 